\title{
Investigation of Compressive Stress on Lumbar Spine due to Whole Body Vibration Exposure in Rotary Tillage Operation
}

\author{
A. Singh ${ }^{1 *}$, N. Nawayseh ${ }^{2}$, L. P. Singh ${ }^{1}$, S. Singh $^{1}$ and H. Singh $^{3}$ \\ ${ }^{1}$ Industrial and Production Engineering Department, Dr. B R Ambedkar National \\ Institute of Technology Jalandhar, Punjab, India \\ *Email:ip.nitj@gmail.com \\ ${ }^{2}$ Mechanical Engineering Department, College of Engineering, University of Sharjah, \\ United Arab Emirates \\ ${ }^{3}$ Mechanical Engineering Department, Guru Nanak Dev Engineering College Ludhiana, \\ Punjab, India
}

\begin{abstract}
The aim of this study is to investigate the compressive stress on lumbar spine due to whole body vibration (WBV) exposure in real field rotary soil tillage operation. The spinal stress was evaluated in terms of daily equivalent static compression dose $\left(S_{\text {ed }}\right)$ with respect to various ride conditions (i.e. forward speed, pulling force and tilling depth). Taguchi's L9 orthogonal array was used to form a systematic set of experiments by varying each ride condition over three levels. Signal-to-noise $(\mathrm{S} / \mathrm{N})$ ratios were computed to analyse the holistic effect of ride conditions among all the experimental conditions. In addition, the power spectral density (PSD) of the acceleration at the seat pan was measured along the dominant axis for each experiment. A second order regression model was developed to predict the real experimental $S_{\text {ed }}$ response. Further, the ride conditions were optimised by using desirability technique with the aim of minimizing $S_{\text {ed }}$ response. The magnitude of daily equivalent static compression dose was found between 0.38 and $0.76 \mathrm{MPa}$ which shows a moderate probability of an adverse health effects as per ISO2631-5: 2004. Statistically, forward speed and pulling force are found to significantly affect the $S_{\text {ed }}$ response with a contribution of $64.43 \%$ and $24.73 \%$, respectively. The PSD indicated that the vibration energy of the acceleration measured on the seat pan depend on the ride conditions. The predicted response of regression model showed $4.56 \%$ error in obtaining the actual experimental values. The optimised forward speed, pulling force and tilling depth levels were found to be $0.6 \mathrm{~m} / \mathrm{s}, 2 \mathrm{kN}$, and $0.10 \mathrm{~m}$, respectively.
\end{abstract}

Keywords: Agricultural tractor, whole-body vibration, ride comfort, daily equivalent static compression dose $\left(\mathrm{S}_{\mathrm{ed}}\right)$, power spectral density (PSD), regression model.

\section{INTRODUCTION}

Conventional soil preparation methods are being mechanized in order to reduce soil preparation time while keeping the same required quality. For example, the increasing demand for wheat and paddy, due to the increase in population, triggered the need to shorten the window period between these two successive crops to speed up the productivity [1]. Tillage is one example of a mechanized agricultural operation used to develop optimal soil conditions required for better crop growth. However, it is a challenging task for the farmers to carry out tillage on a paddy harvested field due to deep cracks and clods formed by stubbles. More or less, this issue is resolved by using rotary 
soil tilling operation that prepares the field in considerably short time. This operation is performed by a tractor mounted rotary tiller coupled to a shaft driven by a three-point linkage (TPL) system. The rotation of the shaft rotates the blades mounted on flanges of rotary tiller. This motion causes cutting and mashing of the clods and helps in mixing the soil with the manures or fertilizers leading to a suitable sowing condition. Those operations of the tractor-mounted machinery together with driving the tractor over uneven field surface conditions result in whole body vibration (WBV) [2]. Vibration transmitted to the driver through the seat pan, backrest, platform and steering wheel contributes greatly to degrading the ride comfort $[3,4]$ especially during prolonged exposure to vibration and/or vibration exposure at frequencies in the vicinity of the resonance frequency of the human body [5]. This may increase the risk of musculoskeletal disorders specially to lower back [6-8] as studies showed a significant association between whole body vibration and low back pain among occupational drivers $[9,10]$.

The majority of past studies that investigated mechanisms to reduce WBV suggested some modifications to tractors and their components. Mehta and Tewari [11] studied the effectiveness of nine seat cushion materials with different thickness, density and composition in attenuating the vibration transmitted to driver's body. The results showed that polyurethane foam of higher density could be used for damping vibrations under dynamic ride conditions. Tewari and Prasad [12] investigated the effect of the backrest inclination as well as the radius of curvature of both the seat pan and backrest on ride comfort in tractors. The study reported that a seat with seat pan radius of curvature of $75 \mathrm{~cm}$ and a back rest with radius of curvature of $30 \mathrm{~cm}$ and an inclination of $10^{\circ}$ could provide a comfortable tractor ride. Some researchers have attempted to provide solutions to improve ride comfort by investigating seat suspensions [13], shock absorbers [14] and axle suspension [15]. Others have investigated the influence of tire inflation system [16], tire pressure and forward speed [17] on ride comfort and reported that tire pressure and forward speed have a significant effect on vibration transmission. In addition, the forward speed on uneven terrain was found to be a prime source of increasing WBV [18]. Therefore, tractor manufacturers made suitable modification in seat suspension, shock absorber, tires and equipped tractors with cab system. Those modification and development have undoubtedly increased the cost of the tractor.

In developing countries like India, most farmers are using old model tractors with normal technology. Moreover, most farmers are not capable of buying a tractor equipped with advanced cab and isolation systems due to the high cost involved. Hence, there is a need to provide a comfortable and safe ride in existing tractors. This can be done through identifying the effect of various typical ride conditions (i.e. forward speed, pulling force and tilling depth) on driver's comfort and health and then optimise the ride conditions for comfort and safety. A predictive model can be developed for this purpose. The ride conditions can then be optimised easily by integrating a suitable optimising approach, like desirability, with the model. Taguchi's method is distinctly applied to analyse the output response in considerably limited number of experiments [19]. The selected ride parameters (speed, pulling force and tilling depth) play major roles in performing rotary tiller operation. Farmers usually choose the speed, pulling force and tilling depth settings as per their own ride convenience without paying much attention to ride comfort. Therefore, it is essential to identify the optimum levels of ride parameters for the betterment of tractor ride comfort. A few studies have dealt with optimising some parameters like cab geometry and suspension element to reduce vibration exposure. For example, Velmurugan et al. [20] investigated and optimised the load, road type, and forward speed conditions with the aim of reducing the vibration exposure. The 
improvement in tractor ride during real field rotary soil tillage operation is the main target of the present study. Therefore, this study attempts to investigate the relative effect of forward speed, pulling force, and tilling depth on the lumbar spine due to whole body vibration exposure in rotary soil tillage operation. The spinal stress is evaluated in terms of daily equivalent static compression dose $\left(S_{\mathrm{ed}}\right)$ as per ISO 2631-5 [21]. It is hypothesized that the ride conditions will significantly affect the daily equivalent static compression dose $\left(\mathrm{S}_{\mathrm{ed}}\right)$.

\section{METHOD}

\section{Design of Experiment}

In order to study the effect of the ride conditions on the equivalent static compression dose $\left(S_{e d}\right)$, an experiment with the forward speed, pulling force and tilling depth as the independent variables and the $S_{\text {ed }}$ as the dependent variable was designed. Each design parameter (i.e. independent variable) was studied under three different levels: forward speed $(0.6,0.7,0.8 \mathrm{~m} / \mathrm{s})$, pulling force $(2,4,6 \mathrm{kN})$, and tilling depth $(0.10,0.12,0.14 \mathrm{~m})$ as shown in Table 1 . These parameters and their levels were chosen by conducting direct interviews with Indian farmers and carrying out some trial experiments. The data of trial experiments were not used in this study. The main experiments were systematically designed by using Taguchi's L 9 orthogonal array. This orthogonal array was used to obtain the minimum number of experiments needed to understand the effect of each design parameter on $S_{\text {ed }}$ response. Further, the orthogonal array was analysed in terms of signal to noise ratios $(\mathrm{S} / \mathrm{N})$ for each experiment [22]. The $\mathrm{S} / \mathrm{N}$ ratios were computed to obtain the optimum ride condition with the aim of reducing $S_{\text {ed }}$ response.

\section{Subject}

Due to limited field availability, one subject was recruited to do the experiments. Increasing the number of subjects requires either using a larger field, which is not available, or performing the experiments for all subjects over the same field. This could influence the soil properties like compactibility, moisture content, etc. and may affect the results.

The recruited subject was male with age of 24 years, stature of $1.52 \mathrm{~m}$, mass of $81 \mathrm{~kg}$, and body mass index of $35.06 \mathrm{~kg} / \mathrm{m}^{2}$. The subject belonged to agricultural background with five years' experience in tractor driving. The purpose of the study was well explained to the subject before carrying out the experiment. In addition, the subject signed an informed consent form for participation in the experiment.

\section{Terrain}

The study was carried out on a post harvested paddy field with dimension $112 \times 75 \mathrm{~m}$. The field was of sandy clay loam soil texture. The percentage of clay, sand, and silt was recorded as $24 \%, 67.15 \%$, and $8.85 \%$, respectively. Soil moisture content was found between $52.1 \%$ to $57.5 \%$ during the experimentation period. Soil compactness was recorded as 14,20 and $28 \mathrm{kPa}$ up to $0.05,0.05$ to 0.10 and 0.10 to $0.15 \mathrm{~m}$ depth levels, respectively. 


\section{Machinery and Apparatus}

The study used a 2014 model tractor 'T' with $55 \mathrm{hp}$. Both the front and rear tires of the tractor were in good condition and the inflation pressure was set as per catalogue recommendation. A 7-feet rotary tiller of $450 \mathrm{~kg}$ comprised C-shaped cutting blades was attached to the tractor. This tiller had 48 blades with $2.137 \mathrm{~m}$ cutting width and $0.15 \mathrm{~m}$ cutting depth. The tractor was equipped with two levers with a standard marking points (i.e. draft- 2,4,6,8,10 and position lever-1,3,5,7,9) in order to control pulling force and depth of tillage. The average forward speed was determined by traditional technique of measuring distance covered in selected gear (i.e. $1^{\text {st }}$ low or 1-L) and duration. The pulling force refers to the force exerted on the draw bar to pull the mounted implement. The pulling force was measured by using dynamometer mounted between the draw bar and the rotary tiller [23]. Tilling depth was recorded manually by using a scale ruler respective position lever setting (i.e. 5, 7 and 9). These lever settings were most commonly used by the farmers to carry out rotary tillage operation.

The whole-body vibration root mean square (r.m.s) levels were measured at the seat pan along the three translational axes (i.e. fore-and-aft -(x), lateral -(y) and vertical (z) axis). A tri-axial seat pad sensor type SV 38V was placed on the seat pan under the ischial tuberosities of the subject and connected to SV 106A six-channel human vibration meter (HVM) as per ISO 2631-1 [24]. In addition, the acceleration power spectral density along the dominant axis was calculated. The vibration levels were measured for one minute with respect to each experiment at a sampling rate of $6 \_\mathrm{kHz}$. A frequency weighting filter was used in order to account for the sensitivity of the human body to different frequencies as per ISO 2631-1 [24].

Table 1. Design parameters and their levels.

\begin{tabular}{lcccc}
\hline \multirow{2}{*}{ Input factors } & \multirow{2}{*}{ Unit } & \multicolumn{3}{c}{ Levels } \\
\cline { 3 - 5 } & & 1 & 2 & 3 \\
\hline Forward speed & $\mathrm{m} / \mathrm{s}$ & 0.6 & 0.7 & 0.8 \\
Pulling force & $\mathrm{kN}$ & 2 & 4 & 6 \\
Tilling depth & $\mathrm{m}$ & 0.10 & 0.12 & 0.14 \\
\hline
\end{tabular}

The $\mathrm{S} / \mathrm{N}$ ratio can be categorized into three types i.e. smaller-the-better, largerthe-better and nominal-the-better. The present study aimed to minimize the output response (i.e. $S_{\text {ed }}$ ), and hence -the-smaller-the-better option was chosen as per Eq. (1) [25]:

$(\mathrm{S} / \mathrm{N}$ Ratio $)=-10 \log \left[\frac{1}{\mathrm{R}\left(\mathrm{y}_{1}^{2}+\mathrm{y}_{2}^{2}+\ldots+\mathrm{y}_{\mathrm{n}}^{2}\right)}\right]$

Where, $\mathrm{y}_{1}, \mathrm{y}_{2}, \ldots, \mathrm{y}_{\mathrm{n}}$ represents the $\mathrm{S}_{\mathrm{ed}}$ responses for each experimental condition replicated R times. The $S_{\text {ed }}$ was determined by using Eq. (2), (3) and (4) as per ISO 26315 [21].

$\mathrm{S}_{\mathrm{ed}}=\left[\left(\mathrm{m}_{\mathrm{k}} \mathrm{D}_{\mathrm{k}}(8)\right)^{6}\right]^{1 / 6}$ 
Where $\mathrm{S}_{\mathrm{ed}}$ is daily equivalent static compression, $\mathrm{m}_{\mathrm{k}}=\mathrm{m}_{\mathrm{x}}=0.015 \mathrm{MPa}, \mathrm{m}_{\mathrm{y}}=0.035 \mathrm{MPa}$, and $\mathrm{m}_{\mathrm{z}}=0.032 \mathrm{MPa}$.

Average daily dose $(\mathrm{MPa}), \mathrm{D}_{\mathrm{k}}(8)=\mathrm{D}_{\mathrm{k}}\left[\frac{480 \text { minutes }}{\text { measurement }} \text { time }\right]^{1 / 6}$

$\mathrm{D}_{\mathrm{k}}=\left[\sum_{\mathrm{i}} \mathrm{A}_{\mathrm{ik}}^{6}\right]^{6}$

Where $\mathrm{D}_{\mathrm{k}}$ is acceleration dose (MPa), $\mathrm{A}_{\mathrm{ik}}$ is the highest peak of the axis (x,y and $\left.\mathrm{z}\right)$; both positive and negative direction peaks are considered for $\mathrm{x}$ and $\mathrm{y}$ axes. For $\mathrm{z}$ axis, positive peak is only considered as per ISO 2631-5 [21].

The recorded vibration data was transferred to SvanPC++ software. It provided the weighted root mean square (r.m.s.) acceleration magnitude of vibration and the acceleration peaks in respective axes. Taguchi's design of experiments was performed in Minitab 16 statistics package software to obtain $\mathrm{S} / \mathrm{N}$ ratios, analysis of variance (ANOVA), percentage contribution $(\mathrm{P})$ for each design parameter, and regression model. The raw acceleration data from the SvanPC++ software was stored in the form of text (.txt) files. Further, the data was analysed in LabVIEW 2014 software to obtain power spectral densities.

\section{RESULTS AND DISCUSSION}

\section{Signal-to-Noise (S/N) Ratio}

The $\mathrm{L}_{9}$ orthogonal array provided a total of nine experimental combinations to determine $\mathrm{S} / \mathrm{N}$ ratios. Each experiment was repeated three times (R1, R2, and R3) and the mean $\mathrm{S}_{\text {ed }}$ response of the three repetitions was calculated and tabulated in Table 2. The acceleration values were found dominant along the $\mathrm{z}$-axis at the seat pan as shown in Figure 1. Prolonged exposure could cause various health issues especially low back pain $[3,26]$.

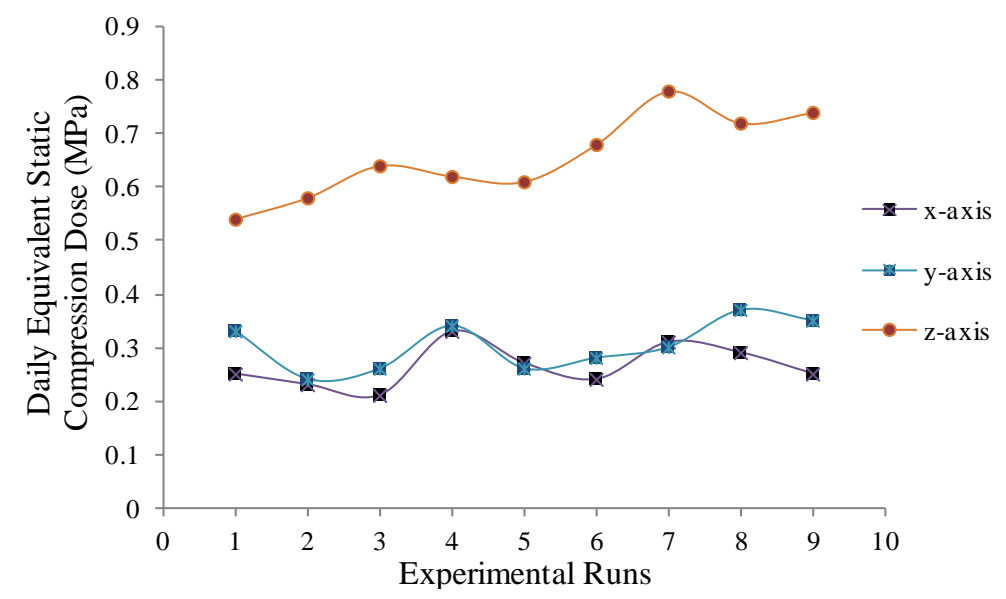

Figure 1. Daily equivalent static compression dose response along the translation axes.

Table 2 shows that the daily equivalent static compression dose $\left(\mathrm{S}_{\mathrm{ed}}\right)$ was in the range of 0.38 to $0.76 \mathrm{MPa}$ among all the experiments. In addition, the $S_{\text {ed }}$ value of $78 \%$ (nine experimental runs) was beyond the recommended limits (i.e. $0.5 \mathrm{MPa}$ ). This could increase the probability of adverse health effect such as injury risk of lumbar spine [21]. 
Table 2. S/N ratio of daily equivalent static compression dose $\left(\mathrm{S}_{\mathrm{ed}}\right)$.

\begin{tabular}{|c|c|c|c|c|c|c|c|c|}
\hline \multirow{2}{*}{$\begin{array}{c}\text { Expt. } \\
\text { run }\end{array}$} & \multirow{2}{*}{$\begin{array}{c}\text { Speed } \\
(\mathrm{m} / \mathrm{s})\end{array}$} & \multirow{2}{*}{$\begin{array}{c}\text { Pulling } \\
\text { force }(\mathrm{kN})\end{array}$} & \multirow{2}{*}{$\begin{array}{c}\text { Tilling } \\
\text { depth }(\mathrm{m})\end{array}$} & \multicolumn{4}{|c|}{$\begin{array}{l}\text { Daily equivalent static } \\
\text { compression dose }\left(\mathrm{S}_{\mathrm{ed}}\right)\end{array}$} & \multirow{2}{*}{$\begin{array}{l}\mathrm{S} / \mathrm{N} \\
\text { ratio } \\
\left(\mathrm{S}_{\mathrm{ed}}\right)\end{array}$} \\
\hline & & & & $\mathrm{R} 1$ & $\mathrm{R} 2$ & R3 & $\mathrm{S}_{\mathrm{ed}}($ Mean $)$ & \\
\hline 1 & 1 & 1 & 1 & 0.41 & 0.37 & 0.35 & 0.38 & 8.49 \\
\hline 2 & 1 & 2 & 2 & 0.45 & 0.48 & 0.46 & 0.46 & 6.68 \\
\hline 3 & 1 & 3 & 3 & 0.52 & 0.51 & 0.54 & 0.52 & 5.62 \\
\hline 4 & 2 & 1 & 2 & 0.51 & 0.56 & 0.53 & 0.53 & 5.46 \\
\hline 5 & 2 & 2 & 3 & 0.54 & 0.56 & 0.51 & 0.54 & 5.41 \\
\hline 6 & 2 & 3 & 1 & 0.55 & 0.53 & 0.58 & 0.55 & 5.14 \\
\hline 7 & 3 & 1 & 3 & 0.56 & 0.57 & 0.59 & 0.57 & 4.83 \\
\hline 8 & 3 & 2 & 1 & 0.59 & 0.59 & 0.62 & 0.60 & 4.44 \\
\hline 9 & 3 & 3 & 2 & 0.78 & 0.74 & 0.76 & 0.76 & 2.38 \\
\hline
\end{tabular}

The mean values of raw $\mathrm{S}_{\mathrm{ed}}$ and $\mathrm{S} / \mathrm{N}$ ratio data of each individual parameter was tabulated in Table 3. The effect of each design parameter on the $S_{\text {ed }}$ can be visualized with the change in the value of respective parameter as shown in Figure 2(a) to 2(c). It was observed that the mean $\mathrm{S} / \mathrm{N}$ ratios decreased with the increase in forward speed and pulling force as presented in Figure 2(a) and 2(b). This means that the daily equivalent static compression dose $\left(\mathrm{S}_{\mathrm{ed}}\right)$ increases with increasing forward speed and pulling force levels. This may result in high acceleration peaks due to increase in vibration magnitude with respect to the increase in forward speed [2,27]. Prolonged exposure to high acceleration should be avoided and controlled as it could affect the ride comfort and diminishes the physical work capacity of tractor driver [28]. Figure 2(c) shows that-the daily equivalent static compression dose response increases slightly with increasing the tilling depth up to the $0.12 \mathrm{~m}$. Subsequently, it showed a sudden decrease with the increase in tilling depth to $0.14 \mathrm{~m}$. It can be stated that the vibration transmitted to the driver's body tend to decrease with increasing the tilling depth from 0.12 to $0.14 \mathrm{~m}$. Kim and Lee [29] reported that the interaction between soil particles and tilling tool could retard the flow of vibration due to the increase in cohesion and friction. Vibration energy tends to propagate inside the field with the increase in depth levels and this may lower its transmission into the driver's body due to increase in distance from the source of vibration.

Table 3. Average values of raw and $\mathrm{S} / \mathrm{N}$ data.

\begin{tabular}{lcccc}
\hline & \multirow{2}{*}{ Parameters } & \multicolumn{3}{c}{ Average values of quality characteristic } \\
\cline { 3 - 5 } Daily static & Forward speed & Level 1 & Level 2 & Level 3 \\
\cline { 3 - 5 } equivalent dose & Pulling force & 6.921 & 5.329 & 3.882 \\
(SN data) & Tilling depth & 6.010 & 5.504 & 4.379 \\
Daily static & Forward speed & 0.4544 & 4.838 & 5.284 \\
equivalent dose & Pulling force & 0.4944 & 0.5411 & 0.6444 \\
(raw data) & Tilling depth & 0.5100 & 0.5333 & 0.6122 \\
\hline
\end{tabular}




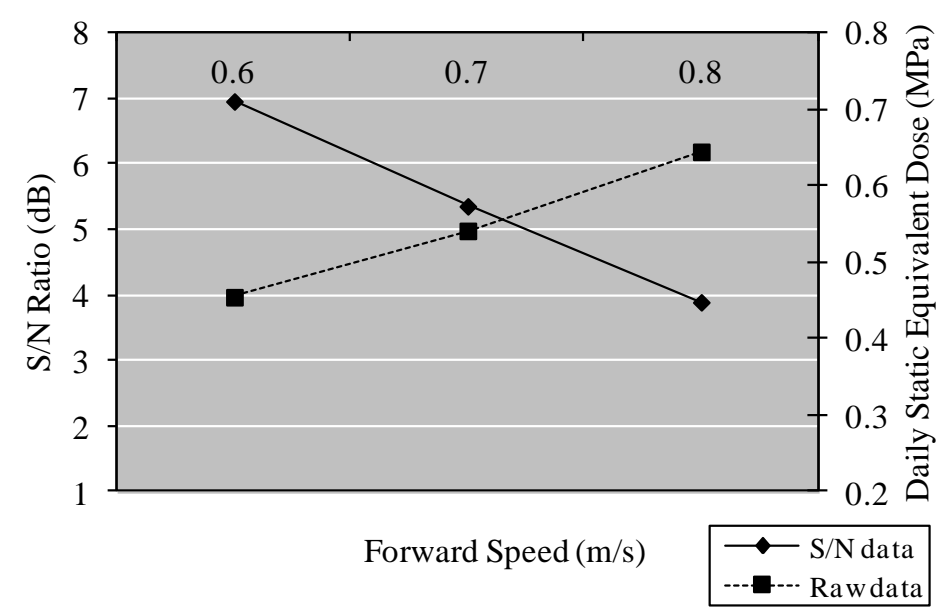

(a)

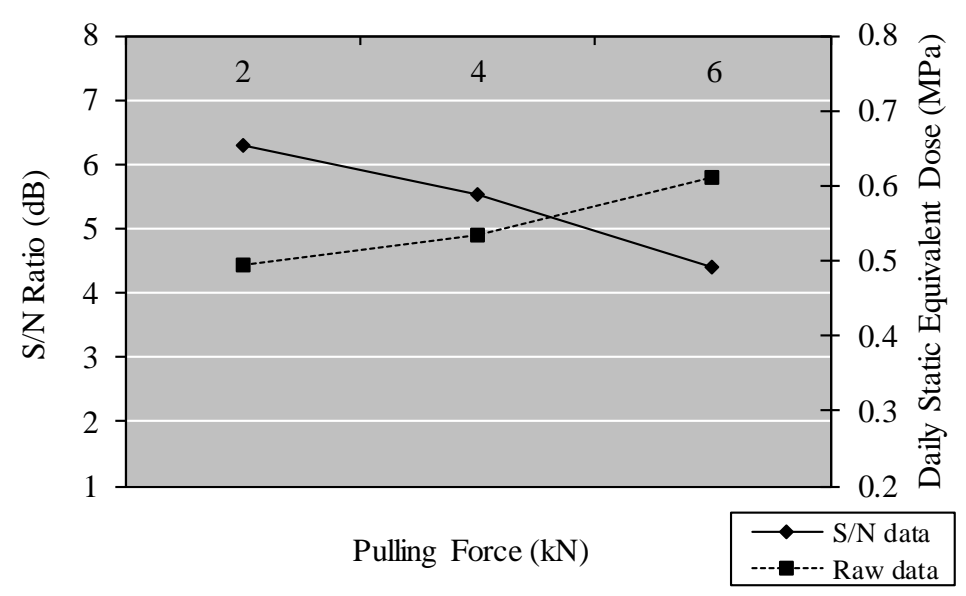

(b)

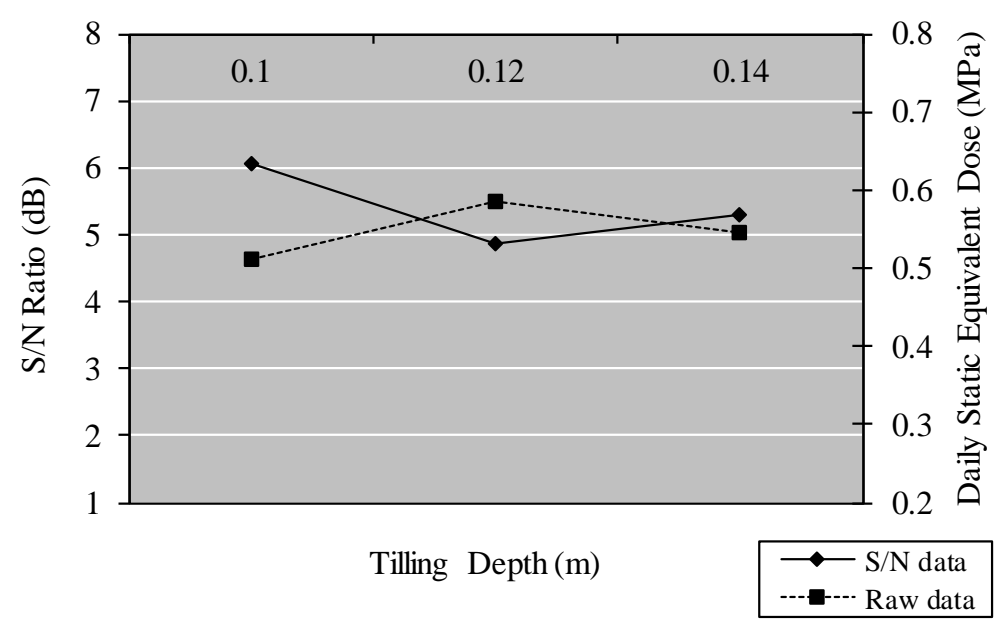

(c)

Figure 2. Effect of design parameters on daily equivalent static compression dose (a) to (c)

The statistical significance of each design parameter on daily equivalent static compression dose was investigated by using analysis of variance (ANOVA). The sequential sum of squares (SeqSS), adjusted mean squares (AdjMS), F- value, P-value 
and percentage contribution $(\mathrm{P})$, delta value and ranking of each parameter were calculated and tabulated in Table 4. The statistical significance was analysed and compared at $95 \%$ confidence level with the tabulated value i.e. $F_{0.05}(2,8)=4.46$, where 2 and 8 corresponds to the degree of freedom (DOF), respectively. It can be seen that the forward speed and pulling force significantly affected the $S_{\text {ed }}$ response $(p \leq 0.05)$. However, the tilling depth was found insignificant parameter to influence the $S_{\text {ed }}$ response. In addition, the contribution percentage of each parameter on affecting the $S_{\text {ed }}$ was computed by Eq. (5) [30].

$\mathrm{P} \%=\frac{\text { Seq }_{\mathrm{SS}}}{\mathrm{Seq} \mathrm{SS}_{\mathrm{T}}} \times 100$

where Seq SS: Individual sequential sum of squares; Seq $\mathrm{SS}_{\mathrm{T}}$ : Total sequential sum of squares.

Table 4 shows that the $S_{\text {ed }}$ response was highly affected by the forward speed $(64.43 \%)$ followed by pulling force $(24.73 \%)$ and tilling depth $(9.83 \%)$. The delta value of each parameter was calculated as the difference between the highest and lowest $\mathrm{S} / \mathrm{N}$ ratio values. The corresponding delta values of forward speed, pulling force, and tilling depth were $3.04,1.87$, and 1.17 , respectively which confirms the relative importance of the studied parameters indicated by the calculated contribution percentage; the delta value represents the ranking of each parameter in terms of its effect on $S_{\text {ed }}$ response with rank 1 corresponds to the parameter with maximum delta value.

Table 4. Analysis of variance for $\mathrm{S} / \mathrm{N}$ ratios.

\begin{tabular}{lcccccccc}
\hline Source & DF & SeqSS & AdjMS & $\begin{array}{c}\text { F- } \\
\text { value }\end{array}$ & $\begin{array}{c}\text { P- } \\
\text { value }\end{array}$ & $\begin{array}{c}\text { \%contribution } \\
(\mathrm{P})\end{array}$ & Delta & Ranking \\
\hline $\begin{array}{l}\text { Forward } \\
\text { speed }\end{array}$ & 2 & 13.92 & 6.96 & 62.89 & $0.01^{*}$ & 64.43 & 3.04 & 1 \\
$\begin{array}{l}\text { Pulling } \\
\text { force }\end{array}$ & 2 & 5.34 & 2.67 & 24.14 & $0.04 *$ & 24.73 & 1.87 & 2 \\
$\begin{array}{l}\text { Tilling } \\
\text { depth }\end{array}$ & 2 & 2.12 & 1.06 & 9.58 & 0.09 & 9.83 & 1.17 & 3 \\
$\begin{array}{l}\text { Residual } \\
\text { error }\end{array}$ & 2 & 0.22 & 0.11 & & & 1.01 & & \\
Total & 8 & 21.60 & & & & 100.00 & & \\
\hline
\end{tabular}

Significant at $95 \%$ confidence level $\left(\mathrm{F}_{0.05,2,8}=4.46\right)$

“*” indicates the most significant factor.

\section{Power Spectral Density (PSD)}

Power spectral density represents the variation in energy with respect to frequency spectrum. Majority of previous studies analysed PSDs in controlled laboratory environment where the input vibration has the same energy over the whole frequency range. Hence, those studies used transfer functions to present their results. In real field experimentation, the vibration energy is not constant over the whole frequency range which makes representing the results using transfer functions misleading. Therefore, it was decided to present the data of this study in the form of r.m.s. acceleration values and power spectral density of the acceleration at the seat pan as used previously [31]. 

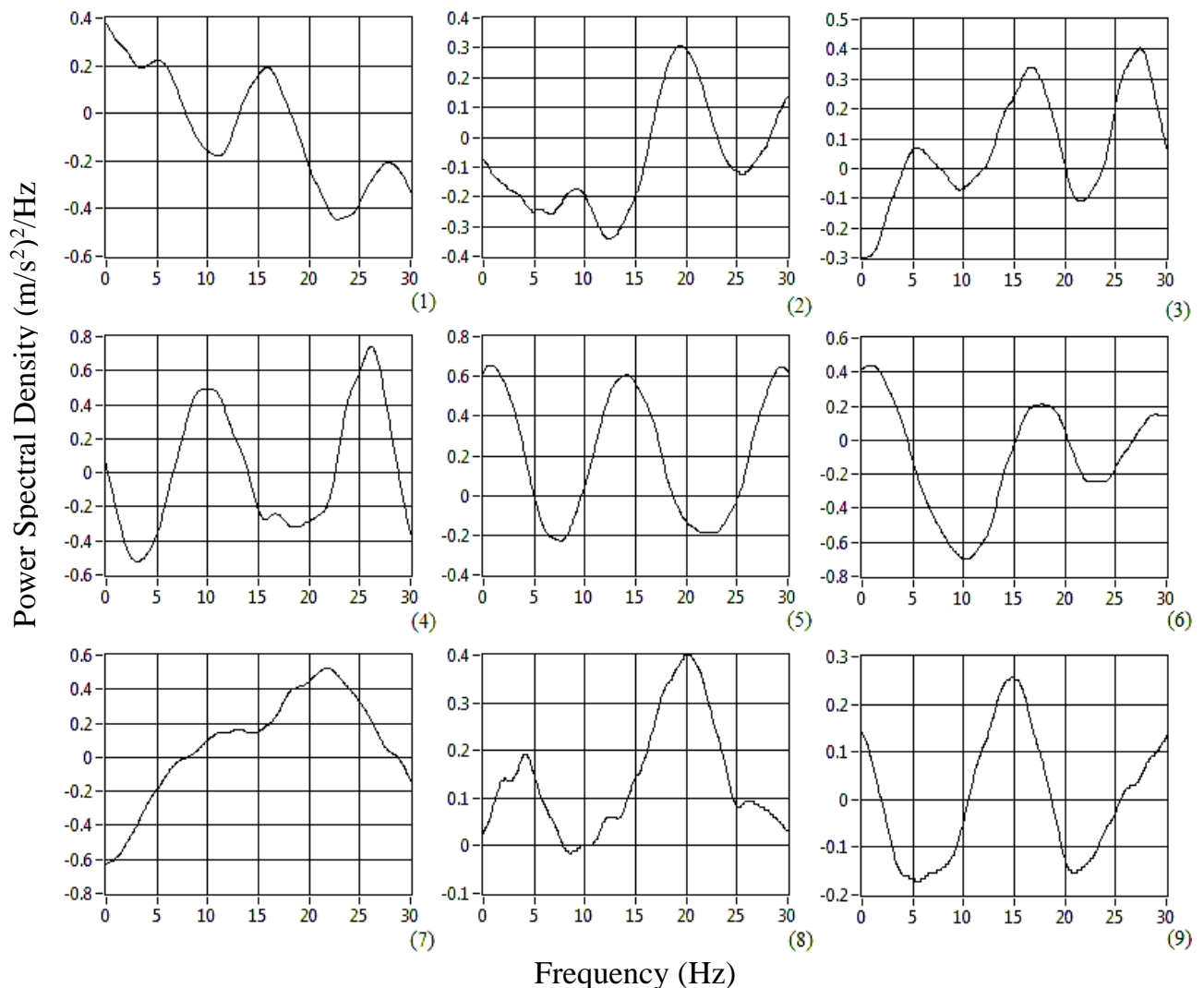

Figure 3. Power spectral density (PSD) of the acceleration measured on the seat pan during the experiments. Number 1 to 9 refer to the experiments as in Table 2.

The raw acceleration data measured along the dominant vertical (z) axis on the seat pan was used to compute the power spectral density for each experiment (1-9) as shown in Figure 3. PSDs of acceleration showed a considerable change in energies at different frequencies for each experiment. PSD showed a varying energy with a minimum of a single peak and maximum of 3 peaks among all the experiments depending on the ride condition. The frequency of first peak was found around $4.6-5 \mathrm{~Hz}$ in experiments number 1,3 and 8 [26,32]. The experiment 5 showed a primary peak at frequency of 13.9 Hz. A second peak was observed at $10 \mathrm{~Hz}$ in experiment $4,15-18 \mathrm{~Hz}$ in experiment $1-3,4$ and 6 and a third peak around 20-27 Hz in experiment 3,4,7 and 8, respectively. Those frequencies coincide with the resonance frequencies of the human body [33-35] and may consequently cause discomfort, abdominal issues, muscle tension and headache [5].

\section{Regression Modelling}

A second order regression model was developed by using the daily equivalent static compression dose $\left(\mathrm{S}_{\mathrm{ed}}\right)$ responses obtained from the conducted experiments. This model was used to predict daily equivalent static compression dose from the studied design parameters. Moreover, the model can be used to obtain the optimal level of each design parameter in order to reduce the daily equivalent static compression dose response. The regression model has been developed as shown in Eq. (6).

$\mathrm{S}_{\mathrm{ed}}=-0.339+0.950$ Speed $(\mathrm{m} / \mathrm{s})+0.02944$ Pulling Force $(\mathrm{kN})+0.861$ Tilling Depth (m) 
$\mathrm{R}^{2}=0.89, \mathrm{R}^{2}$ (Adjusted) $=0.83, \mathrm{R}^{2}($ Predicted $)=0.67$

The mean $\mathrm{S}_{\text {ed }}$ response tabulated in Table 2 was compared with the predicted response using the regression model. A good correlation has been found between actual and predicted responses with an error of $4.56 \%$ as shown in Figure 4. The desirability approach is used for optimising the input factors as per the regression model. The design parameters were optimised by using desirability approach. The desirability (d) value of Eq. (5) was obtained as 0.91 . The results provided optimum levels of forward speed, pulling force, and tilling depth as $0.6 \mathrm{~m} / \mathrm{s}, 2 \mathrm{kN}$, and $0.10 \mathrm{~m}$, respectively. In addition, this approach provided similar optimum levels of each parameter as given by Taguchi's $\mathrm{S} / \mathrm{N}$ ratios shown in Figure 2 in order to obtain minimum $\mathrm{S}_{\text {ed. }}$.

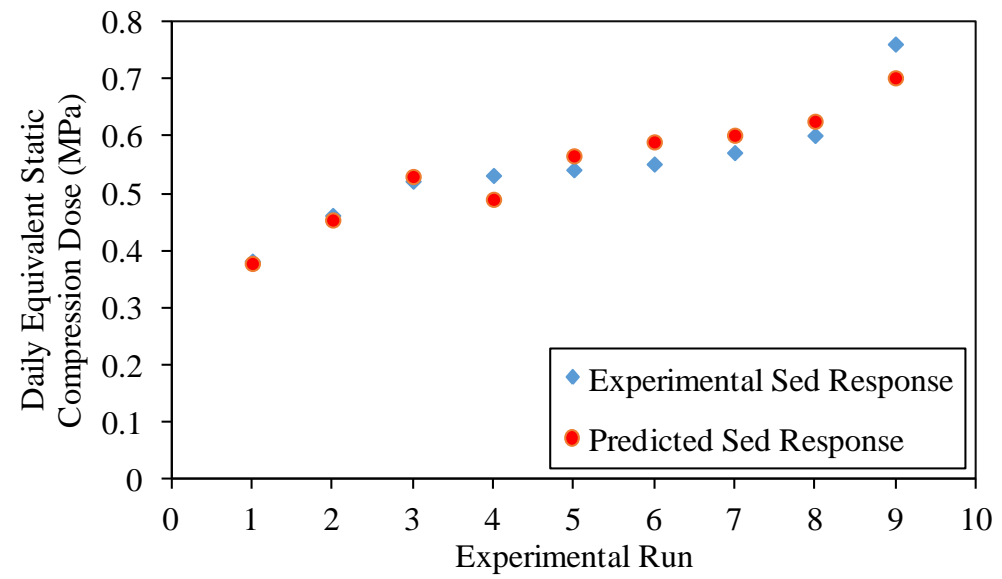

Figure 4. Comparison between experimental and predicted $S_{\text {ed }}$ response.

\section{CONCLUSION}

Forward speed and pulling force were found significant parameters $(p \leq 0.05)$ in influencing the $S_{\text {ed }}$ response with a contribution percentage of 64.43 and $27.73 \%$, respectively. The power spectral density depicted various dominant frequencies that help understand the effect of ride conditions on health and comfort in real conditions. A proposed regression model showed a good correlation between the actual and predicted $S_{\text {ed }}$ response with $4.56 \%$ mean error. Both Taguchi's and desirability approach provided similar optimum levels of each design parameter with the aim of minimizing daily equivalent static compression dose $\left(\mathrm{S}_{\mathrm{ed}}\right)$. In addition to the parameters studied in the present study, it is suggested to include other parameters that might affect ride comfort in future studies. For example, the influence of tire inflation condition, seat condition and other rotary tiller blade shapes, such as J or L blade shapes, may be studied in the future.

\section{ACKNOWLEDGEMENT}

The authors are grateful to The Institution of Engineers (IEI), India for providing the financial support to carry out the present study [Grant Code: RDDR2016067]. Authors would thank The Department of Farm Machinery and Power Engineering, Punjab Agricultural University, Ludhiana, Punjab, India for providing experimental facilities. The authors would like also to thank the subject who performed the experiments. 


\section{REFERENCES}

[1] Prakash A, Manes GS, Dixit A, Singh M. Performance Status of Rotavators being Manufactured in Punjab. Journal of The Institution of Engineers (India): Series A 2013;94(1):53-8.

[2] Mehta CR, Tiwari PS, Varshney AC. Ride Vibrations on a $7.5 \mathrm{~kW}$ Rotary Power Tiller. Journal of Agricultural Engineering Research 1997;66:169-76.

[3] Taylor P, Village J, Trask C. Assessing whole body vibration exposure for use in epidemiological studies of back injuries:measurements, observations and selfreports. Ergonomics. 2012;55(4):37-41.

[4] Park M, Fukuda T, Kim T, Maeda S. Health Risk Evaluation of Whole-body Vibration by ISO 2631-5 and ISO 2631-1 for Operators of Agricultural Tractors and Recreational Vehicles. Industrial Health 2013;51:364-70.

[5] Griffin MJ. Handbook of Human Vibration. London: Academic Press; 1990.

[6] Dewangan KN, Shahmir A, Rakheja S. Vertical and Fore-Aft Seat-to-Head Transmissibility Response to Vertical Whole Body Vibration: Gender and Anthropometric Effects. Journal of Low Frequency Noise, Vibration and Active Control 2013;32(1):11-40.

[7] Singh A, Singh LP, Singh S, Singh H, Prakash C. Investigation of occupational whole-body vibration exposure among Indian tractor drivers. International Journal of Human Factors and Ergonomics 2018;5(2):151-65.

[8] Boshuizen HC, Bongers PM. Self-reported back pain in fork-lift truck and freightcontainer tractor drivers exposed to whole body vibration. Spine 1992;17(1):5965.

[9] Tiemessen AI, Hulshof CT, Dresen MS. Low back pain in drivers exposed to whole body vibration: analysis of a dose - response pattern. Occupational and Environmental Medicine 2016;65(10):667-75.

[10] Najenson DA, Santo Y, Masharawi Y, Ushvaev MK, Kalichman L. Low back pain among professional bus drivers : ergonomic and occupational-psychosocial risk factors. The Israel Medical Association Journal 2010;12:26-31.

[11] Mehta CR, Tewari VK. Damping characteristics of seat cushion materials for tractor ride comfort. Journal of Terramechanics 2010;47(6):401-406.

[12] Tewari VK, Prasad N. Optimum seat pan and back-rest parameters for a comfortable tractor seat. Ergonomics. 2000;43(2):167-186.

[13] Velmurugan P, Kumaraswamidhas LA. Influence of road surfaces on whole body vibration for suspended cabin tractor semitrailer drivers. Journal of Low Frequency Noise, Vibration and Active Control 2012;31(2):75-84.

[14] Deprez KA, Moshou D, Ramon H. Comfort improvement of a nonlinear suspension using global optimization and in situ measurements. Journal of Sound and Vibration 2005;284:1003-1014.

[15] Lehtonen TJ, Juhala M. Predicting the ride behaviour of a suspended agricultural tractor. International Journal of Vehicle Systems Modelling and Testing 2005;1(1/2/3):131-142.

[16] Adams BT, Reid JF, Hummel JW, Zhang Q, Hoeft RG. Effects of central tire inflation systems on ride quality of agricultural vehicles. Journal of Terramechanics 2004;41:199-207.

[17] Nguyen VN, Inaba S. Effects of tire inflation pressure and tractor velocity on dynamic wheel load and rear axle vibrations. Journal of Terramechanics 2011;48(1):3-16. 
[18] Scarlett AJ. Whole-body vibration : Evaluation of emission and exposure levels arising from agricultural tractors. Journal of Terramechanics 2007;44:65-73.

[19] Huang M, Hung Y, Yang Z. Validation of a method using Taguchi, response surface, neural network, and genetic algorithm. Measurement 2016;94:284-294.

[20] Sankaranarayanasamy K. Optimisation of whole body vibration analysis for suspended cabin tractor semitrailer P. International Journal of Vehicle Noise and Vibration 2012;8(2):152-165.

[21] International Organization of Standardization (2631-5). Mechanical vibration and shock - Evaluation of human exposure to whole-body vibration - Part 5: Method for evaluation of vibration containing multiple shocks. 2004.

[22] Bagci E, Aykut S. A study of Taguchi optimization method for identifying optimum surface roughness in CNC face milling of cobalt-based alloy (stellite 6). International Journal of Advanced Manufacturing and Technology 2006;29:940947.

[23] Chen Y, Mclaughlin NB, Tessier S. Double extended octagonal ring (DEOR) drawbar dynamometer. Soil Tillage and Research 2007;93:462-471.

[24] International Organization of Standardization (2631-1). Mechanical Vibraton and Shock-Evaluation of Human Exposure to Whole Body Vibration-Part 1: Genereal Requirements. 1997.

[25] Antony J. Teaching the Taguchi method to industrial engineers. Work Study. 2001;50(4):141-149.

[26] Harsha SP, Desta M, Prashanth AS, Saran VH. Measurement and bio-dynamic model development of seated human subjects exposed to low frequency vibration environment. International Journal of Vehicle Noise and Vibration 2014;10(1/2):1-24.

[27] Taghizadeh-alisaraei A. Analysis of annoying shocks transferred from tractor seat using vibration signals and statistical methods. Computers and Electronics in Agriculture 2017;141:160-170.

[28] Sam B, Kathirvel K. Vibration Characteristics of Walking and Riding Type Power Tillers. Biosystems Engineering 2006;95(4):517-528.

[29] Kim D, Lee J. Propagation and attenuation characteristics of various ground vibrations. Soil Dynamics and Earthquake Engineering 2000;19:115-126.

[30] Singh A, Singh LP, Singh S, Singh H, Kumar N. Evaluation And Analysis Of Occupational Ride Comfort In Rotary Soil Tillage Operation Evaluation and analysis of occupational ride comfort in rotary soil tillage operation. Measurement 2018;131:19-27.

[31] Nawayseh N. Tri-Axial Vibration of the Head of Car Driver under Different Seating Conditions. International Journal of Automotive and Mechanical Engineering. 2018;15(2):5178-5194.

[32] Toward MG, Griffin MJ. The transmission of vertical vibration through seats: Influence of the characteristics of the human body. Journal of Sound and Vibration 2011;330(26):6526-6543.

[33] Nawayseh N, Griffin MJ. Power absorbed during whole-body vertical vibration : Effects of sitting posture, backrest, and footrest. Journal of Sound and Vibration 2010;329(14):2928-2938.

[34] Nawayseh N, Griffin MJ. A model of the vertical apparent mass and the fore-andaft cross-axis apparent mass of the human body during vertical whole-body vibration. Journal of Sound and Vibration 2009;319:719-730.

[35] Singh A, Nawayseh N, Singh LP, Singh S, Singh H. Whole Body Vibration 
Exposure during Rotary Soil Tillage Operation: The Relative Importance of Tractor Velocity, Draft and Soil Tillage Depth. International Journal of Automotive and Mechanical Engineering 2018;15(4):5927-5940. 